\title{
Fast Suzuki-Miyaura Cross-Coupling Reaction with Hexacationic Triarylphosphine Bn-Dendriphos as Ligand
}

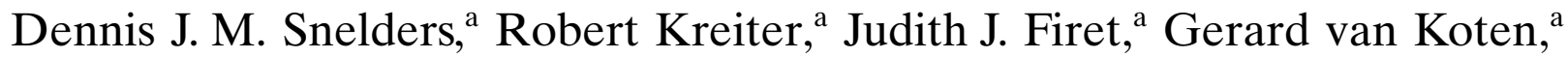 \\ and Robertus J. M. Klein Gebbink ${ }^{\mathrm{a}, *}$ \\ a Faculty of Science, Chemical Biology and Organic Chemistry. Utrecht University, Padualaan 8, $3548 \mathrm{CH}$ Utrecht, The \\ Netherlands \\ Phone: (+31)-30-252-3120; fax: (+31)-30-252-3615; e-mail: r.j.m.kleingebbink@uu.nl
}

Received: July 25, 2007; Revised: September 28, 2007; Published online: January 4, 2008

\begin{abstract}
The application of hexa[(dimethylamino)methyl]-functionalized triphenylphosphine (1) and its benzylammonium salt, Bn-Dendriphos (2), in the Suzuki-Miyaura cross-coupling of aryl bromides with arylboronic acids is described. The 3,5-bis[(benzyldimethylammonio)methyl] substitution pattern in $\mathbf{2}$ leads to a rate enhancement compared to both the non-ionic parent compound $\mathbf{1}$ and triphenylphospine $\left(\mathrm{PPh}_{3}\right)$ itself. At the same time, the resulting catalytic
\end{abstract}

species are stable towards palladium black formation, even at a phosphine/palladium ratio of 1 . These observations are attributed to the presence of a total of six ammonium groups in the backbone of the phosphine ligand, which presumably leads to an unsaturated phosphine-palladium complex.

Keywords: C $-\mathrm{C}$ coupling; Dendriphos; palladium; phosphine; Suzuki-Miyaura reaction

\section{Introduction}

Recently, we developed a novel class of hexaionic phosphines derived from the hexa[(dimethylamino)methyl]-functionalized triarylphosphine core molecule $\mathbf{1}\left[\mathrm{P}(\mathrm{NCN})_{3}\right.$, Figure 1], for which we coined the name<smiles>CNCc1cc(CN(C)C)cc(P(c2cc(CN(C)C)cc(CN(C)C)c2)c2cc(CN(C)C)cc(CN(C)C)c2)c1</smiles>

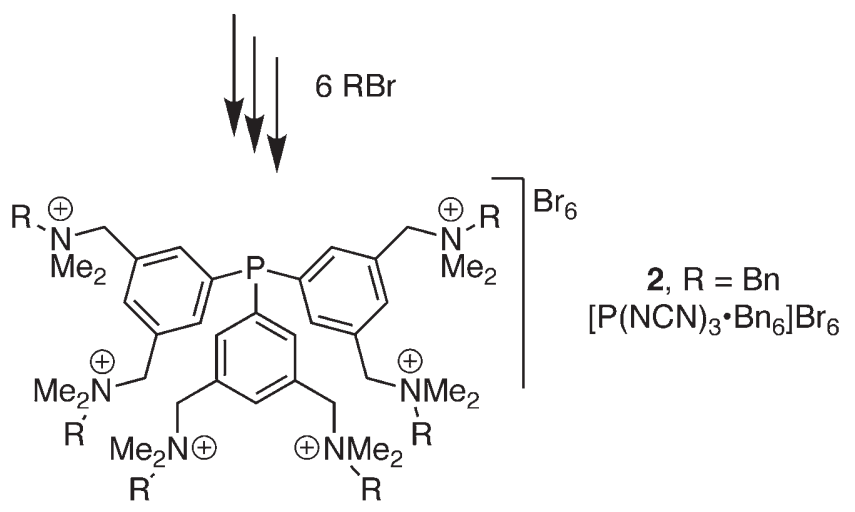

Figure 1. Hexaamino- and hexaammonium-functionalized triarylphosphines $\mathbf{1}$ and $\mathbf{2}$.
Dendriphos $\left\{\left[\mathrm{P}(\mathrm{NCN})_{3} \cdot \mathrm{R}_{6}\right] \mathrm{X}_{6}, \mathrm{R}=\mathrm{Me}, \mathrm{Bn}\right.$ or Fréchet wedge and $\mathrm{X}=\mathrm{Br}$ or $\mathrm{I}\}{ }^{[1]}$ These novel ligands combine a triarylphosphine core with a shell of six ammonium groups. The latter feature makes this series of dendritic ligands very versatile, as it enables them to act as phase-transfer agents and opens the way for catalyst recovery by means of a biphasic work-up or via nanofiltration. Both NMR and molecular modelling experiments suggested the use of these hexacationic phosphines as bulky ligands. ${ }^{[1]}$ At the same time, based on the solubility range of these ligands, applications in both $\mathrm{H}_{2} \mathrm{O}$ and $\mathrm{MeOH}$, as well as in organic solvents, can be envisioned.

As our first investigation into the use of this class of ligands in homogeneous catalysis, we applied BnDendriphos (2, $\mathrm{R}=\mathrm{Bn}$, soluble in $\mathrm{MeOH})$ in the Suzuki-Miyaura reaction, which is a widely used, Pdmediated $\mathrm{C}-\mathrm{C}$ coupling method, tolerating numerous functional groups. ${ }^{[2]}$ The latter feature makes this reaction feasible for the preparation of, e.g., natural products or pharmaceuticals. ${ }^{[3]}$ Most of these reactions apply aryl halides and boronic acids; boronic acids being much less toxic and easier to handle than (main group) organometallic compounds used in other cross-coupling reactions. ${ }^{[4]}$ Among the successful examples of catalysts for this reaction are ligand-free $\mathrm{Pd}$ species $^{[5]}$ and Pd complexes using various types of ligands, such as $\mathrm{N}$-heterocyclic carbenes ${ }^{[6]}$ and sterically constrained and electron-rich monodentate phosphine 
ligands, such as bulky trialkylphosphines, ${ }^{[7]}$ biarylphosphines $^{[8]}$ and ferrocenylphosphines. ${ }^{[9]}$ In this report, we present our first results concerning the application of hexacationic triarylphosphine Bn-Dendriphos (2) in this reaction and the remarkable rate-enhancing effect of the 3,5-bis[(benzyldimethylammonio)methyl] substitution pattern in its ligand structure.

\section{Results and Discussion}

As model reaction we selected the coupling of 4-tolylboronic acid and methyl 4-bromobenzoate giving methyl 4-tolylbenzoic ester 3 [Eq. (1)]. $\operatorname{Pd}(\mathrm{dba})_{2}$ was

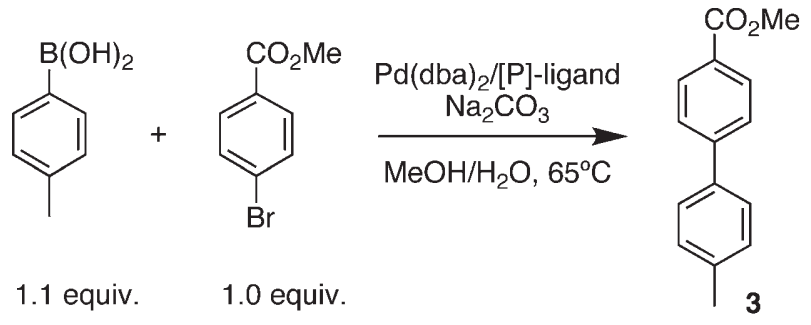

used as palladium source and $\mathrm{Na}_{2} \mathrm{CO}_{3}$ (2 equivs. with respect to the aryl bromide) as base in a mixture of methanol and water $(9 / 1, \mathrm{v} / \mathrm{v})$ at $65^{\circ} \mathrm{C}$. The hexaionic phosphine $\left[\mathrm{P}(\mathrm{NCN})_{3} \cdot \mathrm{Bn}_{6}\right] \mathrm{Br}_{6}(\mathbf{2}, \mathrm{Bn}-$ Dendriphos $)$ was tested as donor ligand at $3,1,0.1$, and $0.01 \mathrm{~mol} \%$ of $\mathrm{Pd}$ loading. The number of equivalents of phosphine per palladium center was varied from 4 down to 1 . Furthermore, hexaionic 2 was compared to the parent phosphine $\mathrm{P}(\mathrm{NCN})_{3}(\mathbf{1})$ as well as to $\mathrm{PPh}_{3}$. Control reactions were run in the absence of phosphine, base or palladium source. The catalyst performance is expressed as the time at which the coupling yield reached $50 \%$, as well as the maximum obtained yield and the required reaction time (Table 1 ).

These experiments show that $\mathbf{2}$ exhibited a behaviour that is dramatically different from that of the benchmark ligand $\mathrm{PPh}_{3}$. For example, when four equivalents of 2 were applied at $1 \mathrm{~mol} \% \mathrm{Pd}$ loading, a quantitative yield was reached within ten minutes, whereas in the case of $\mathrm{PPh}_{3}$ this took up to seven hours. Neutral ligand $\mathbf{1}$ also gave a lower rate than that found for hexaionic $\mathbf{2}$ (Figure 2), but performed better than $\mathrm{PPh}_{3}{ }^{[10]}$

Importantly, due to the activated nature of the aryl bromide employed, the present benchmark reaction is extremely fast. In fact, in the absence of any ligand, a quantitative yield is obtained after $90 \mathrm{~min}$ at $3 \mathrm{~mol} \%$ $\mathrm{Pd}$, even though rapid $\mathrm{Pd}$ black formation is observed. At $0.01 \mathrm{~mol} \% \mathrm{Pd}$, the ligand-free process resulted in a similar activity, reaching a maximum yield of $90 \%$ after $20 \mathrm{~min}$. These results are in line with those found by Bumagin et al., who reported a ligand- and stabilizer-free, Pd-catalyzed Suzuki reac-
Table 1. Selected catalytic data for the reaction of Eq. (1).

\begin{tabular}{|c|c|c|c|c|c|}
\hline Entry & $\begin{array}{c}\mathrm{Pd}(\mathrm{dba})_{2} \\
|\mathrm{~mol} \%|\end{array}$ & Phosphine & $\begin{array}{c}\text { Phosphine/Pd } \\
\text { Ratio }\end{array}$ & Time $\left[\left.\min \right|^{|\mathrm{a}|}\right.$ & 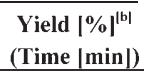 \\
\hline 1 & 3 & 2 & 4 & $2-4$ & $100(10)$ \\
\hline 2 & 3 & $\mathrm{PPh}_{3}$ & 4 & 180 & $88(420)$ \\
\hline 3 & 3 & - & 0 & $5^{[\mathrm{c}]}$ & $99(90)^{[c]}$ \\
\hline 4 & 1 & 2 & 4 & $3-5$ & $100(10)$ \\
\hline 5 & 1 & 1 & 4 & $15-20$ & $100(130)$ \\
\hline 6 & 1 & $\mathrm{PPh}_{3}$ & 4 & 120 & $96(420)$ \\
\hline 7 & 0.1 & 2 & 4 & 4 & $100(10)$ \\
\hline 8 & 0.01 & 2 & 4 & 20 & $96(60)$ \\
\hline 9 & 0.01 & 2 & 2 & 10 & $99(60)$ \\
\hline 10 & 0.01 & 2 & 1 & 4 & $98(60)$ \\
\hline 11 & 0.01 & - & 0 & $5^{[\mathrm{c}]}$ & $90(20)^{[c]}$ \\
\hline 12 & - & 2 & - & - & $0(120)$ \\
\hline 13 & 3 & 2 & 4 & - & $0(120)^{[\mathrm{d}]}$ \\
\hline
\end{tabular}

[a] Time at which the GC yield reached $50 \%$.

[b] Yield of the cross-coupled product, determined by GC.

[c] Pd black was formed.

[d] No base was used.

tion in water. ${ }^{[5 a, b]}$ Similar results at very low catalyst loadings were reported by de Vries et al. ${ }^{[\mathrm{c}, \mathrm{d}]}$ The use of a phosphine ligand stabilizes the catalyst and can prevent the formation of Pd black. Due to the inhibitory role played by the phosphine ligand in the case of $\mathrm{PPh}_{3},{ }^{[4]}$ the reaction is slowed down dramatically. Remarkably, the use of an equal amount of hexaionic $\mathbf{2}$ does not show any decrease in reaction rate, while still preventing $\mathrm{Pd}$ black formation. As a result of high activity combined with high stability, quantitative yield is obtained within $10 \mathrm{~min}$, even at $0.1 \mathrm{~mol} \% \mathrm{Pd}$ loading.

To test the lower limit of catalyst concentration, the Pd concentration was lowered from 3 , via 1 and 0.1 to $0.01 \mathrm{~mol} \%$ using each time four equivalents of 2 (Table 1, entries 1, 4, 7 and 8). These experiments show that only at a concentration of $0.01 \mathrm{~mol} \% \mathrm{Pd}$ does the reaction rate start to drop. When the ratio of ligand 2 to $\mathrm{Pd}$ was decreased from $4: 1$ to $2: 1$ and $1: 1$ at a Pd loading of $0.01 \mathrm{~mol} \%$, a slight increase in re-

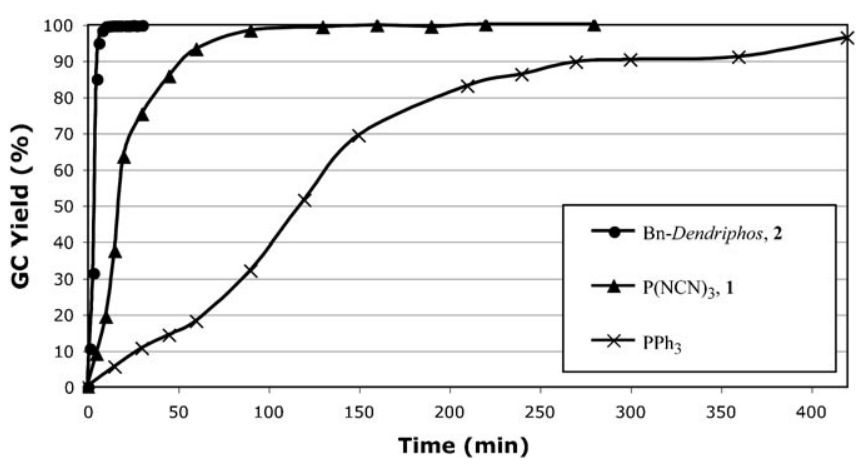

Figure 2. The effect of the ligand on the reaction of Eq. (1) at $1 \mathrm{~mol} \% \mathrm{Pd}$ loading. In each case a phosphine/palladium ratio of 4 was used. 


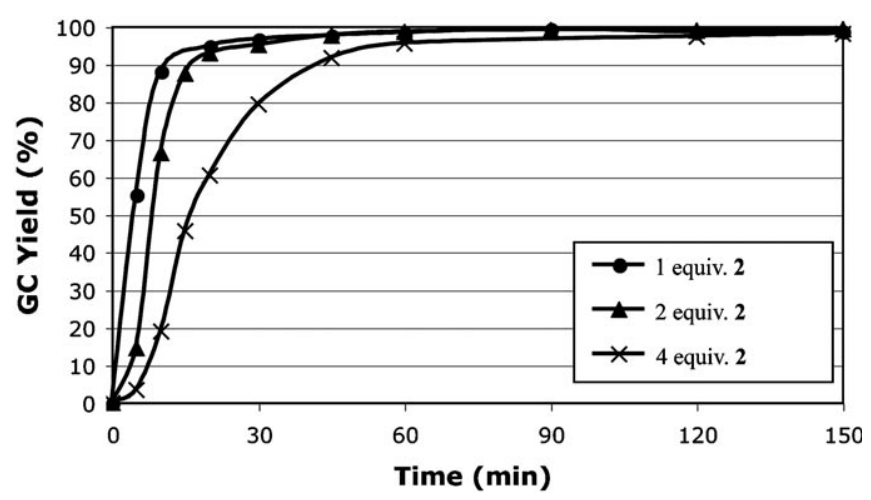

Figure 3. The effect of ligand/Pd ratio on the reaction of Eq. (1) at $0.01 \mathrm{~mol} \% \mathrm{Pd}$ loading using Bn-Dendriphos.

action rate was seen, while at the same time still no Pd black formation was observed (Figure 3).

To investigate the influence of the ammonium groups in Bn-Dendriphos on the reaction, $\mathbf{2}$ was tested in the absence of Pd (Table 1, entry 12). Ammonium salt-promoted $\mathrm{C}-\mathrm{C}$ coupling reactions with $^{[11 \mathrm{~b}]}$ and without ${ }^{[11 \mathrm{a}]} \mathrm{Pd}$ were reported before. The reported activities in the 'absence' of Pd were recently rationalized by the presence of trace amounts of metal in the applied base. ${ }^{[11 c]}$ In our case, however, no conversion was observed in the absence of added $\mathrm{Pd}$. Therefore we believe that the activity observed originates from a homogeneous Bn-Dendriphos-Pd complex. In previous studies it was noted that aryl halides can be reduced by primary and secondary alcohols in the presence of a $\operatorname{Pd}(0)$ source and a base. ${ }^{[8 c, 12]}$ In our experiments, however, no detrimental effect of the use of $\mathrm{MeOH}$ was observed.

The performance of our catalytic system was further probed by performing the reaction with several non-activated and deactivated aryl bromides, as well as with some challenging arylboronic acids [Eq. (2) and Table 2].

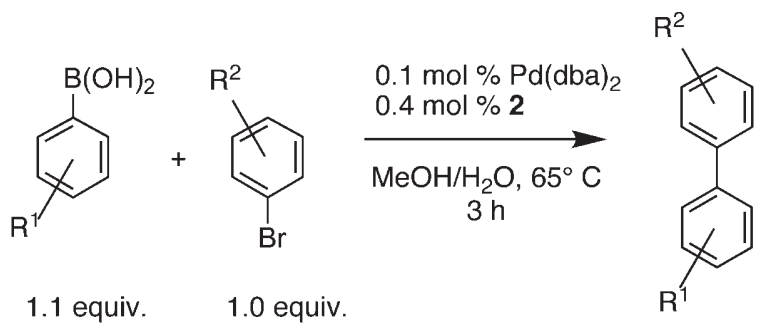

The results in Table 2 show that several aryl boronic acids can be coupled with the same efficiency as observed for 4-tolylboronic acid. Changing the aryl bromide, however, leads to a decrease in the observed reaction rate. After $3 \mathrm{~h}$ of reaction time, moderate yields were obtained for most aryl bromides. Even
Table 2. Catalytic data for the reaction of Eq. (2).

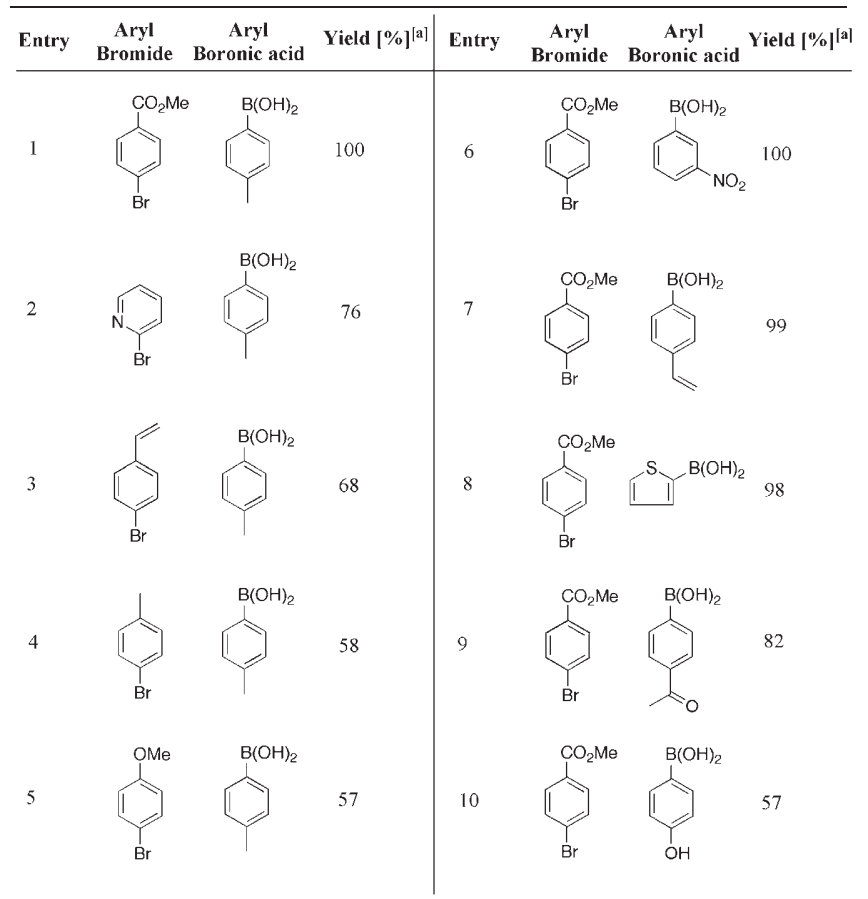

[a] Yield of the cross-coupled product, determined by GC after $3 \mathrm{~h}$ of reaction time.

though Pd black was never observed, the yield increased only marginally by letting the reactions run for an additional $3 \mathrm{~h}$. This suggests that our reaction conditions need further optimization for coupling of more challenging substrates. We are currently performing these investigations.

Our results clearly indicate that hexaionic phosphine 2 can stabilize a $\operatorname{Pd}(0 / \mathrm{II})$ center, without leading to inhibition of the reaction rate, as seen with the benchmark ligand $\mathrm{PPh}_{3}$. It can thus be concluded that 2 has a very low inhibition factor. ${ }^{[13]}$ This indicates that 2 leads to a preferential formation of coordinatively unsaturated phosphine $\operatorname{Pd}(0)$ species. The relatively small observed difference in activity between high and low L:Pd ratios (Figure 3) supports this view. Similar behaviour has been described for bulky $^{[7 b]}$ or bowl-shaped ${ }^{[14]}$ phosphine ligands, but never for phosphine ligands based on a triarylphosphine having a shell of ionic groups. Recently, an $\mathrm{m}$ carboxylic acid-functionalized triphenylphosphine ligand ( $m$-TPPTC) was reported, which showed increased reactivity in Sonogashira cross-couplings compared to its sulfonated analogue (TPPTS). ${ }^{[15]}$ In this case however, the authors rationalize the results by the increased basicity of the ligand. The results for $\mathbf{1}$ and $\mathbf{2}$ are in line with the molecular modelling and coordination experiments on these ligands, reported elsewhere. ${ }^{[1,16]}$ Based on these studies we predicted enlarged cone angles and a bulky behaviour for $\mathbf{2}$. We 
believe that in our case the Coulombic repulsion between neighbouring phosphine ligands acts as a 'pseudo-bulk' and facilitates dissociation of $\mathbf{2}$ from the $\mathrm{Pd}$ center, allowing in situ formation of coordinatively highly unsaturated and catalytically active phosphine $\operatorname{Pd}(0)$ species.

\section{Conclusions}

The monodentate, hexacationic triarylphosphine ligand 2 leads, in combination with $\mathrm{Pd}(\mathrm{dba})_{2}$, to an efficient catalytic system for the Suzuki-Miyaura crosscoupling reaction. From the comparison with the nonionic parent compound as well as the benchmark ligand $\mathrm{PPh}_{3}$, the beneficial effect of the six ammonium groups on the reaction rate is apparent. Lowering the $2 / \mathrm{Pd}(\mathrm{dba})_{2}$ molar ratio from 4 to 1 resulted in a slight increase of activity, without noticeable effect on the stability of the palladium site in the complex. This indicates a preferential formation of coordinatively unsaturated $\mathrm{Pd}$ complexes, which is a property that could be beneficial in a wide range of catalytic applications. Currently, we are further investigating the application of 2 and other Dendriphos ligands ${ }^{[1]}$ for the catalytic conversion of more challenging substrates such as aryl chlorides. Application of these ligands in other metal-catalyzed transformations, are also envisaged.

\section{Experimental Section}

\section{General Remarks}

All catalytic runs were carried out in a parallel reactor setup, using degassed solvents. $\mathrm{Pd}(\mathrm{dba})_{2},{ }^{[17]} \mathrm{P}(\mathrm{NCN})_{3}(\mathbf{1}),{ }^{[16]}$ and $\mathrm{Bn}$-Dendriphos $(\mathbf{2})^{[1]}$ were prepared according to previously reported procedures. Aryl bromides and arylboronic acids were obtained from Acros Chimica and used without further purification. GC measurements were performed on a Perkin-Elmer AutoSystem XL gas chromatograph using pentadecane as an internal standard.

\section{Synthesis of 4-Tolylboronic Acid}

To a solution of 4-bromotoluene $(5.0 \mathrm{~mL}, 40.62 \mathrm{mmol})$ in dry, degassed THF $n$-BuLi $(30.0 \mathrm{~mL}, 1.6 \mathrm{M}, 48.00 \mathrm{mmol})$ was added dropwise at $-100^{\circ} \mathrm{C}$. The mixture was stirred for $15 \mathrm{~min}, \mathrm{~B}(\mathrm{O}-i-\mathrm{Pr})_{3}(9.0 \mathrm{~mL}, 39.00 \mathrm{mmol})$ was added dropwise and the mixture was allowed to warm up to room temperature. The product was extracted with $\mathrm{NaOH}(1 \mathrm{M}, 3 \times$ $30 \mathrm{~mL}$ ). The aqueous layer was acidified with concentrated $\mathrm{HCl}$ and extracted with ethyl acetate $(3 \times 30 \mathrm{~mL})$. The organic layer was dried on $\mathrm{MgSO}_{4}$, filtered and evaporated to dryness. The resulting crude product was purified by recrystallization from $\mathrm{H}_{2} \mathrm{O}$. Yield: $3.81 \mathrm{~g} \quad(72 \%)$. ${ }^{1} \mathrm{H}$ NMR (300 MHz, acetone- $\left.d_{6}\right): \delta=7.76\left(\mathrm{~d}, 2 \mathrm{H}, J_{\mathrm{H}, \mathrm{H}}=7.8 \mathrm{~Hz}, \mathrm{ArH}\right)$, $7.16\left(\mathrm{~d}, 2 \mathrm{H}, J_{\mathrm{H}, \mathrm{H}}=7.2 \mathrm{~Hz}, \operatorname{ArH}\right), 7.03(\mathrm{~s}, 2 \mathrm{H}, \mathrm{OH}), 2.32(\mathrm{~s}$, $\left.3 \mathrm{H}, \quad \mathrm{CH}_{3}\right) ;{ }^{13} \mathrm{C} \mathrm{NMR} \quad\left(300 \mathrm{MHz}\right.$, acetone- $\left.d_{6}\right): \quad \delta=141.5$, 135.7, $129.7(\mathrm{ArC}), 22.20\left(\mathrm{CH}_{3}\right)$.

\section{General Procedure for the Suzuki-Miyaura Reaction}

Arylboronic acid $(2.57 \mathrm{mmol})$, aryl bromide $(2.33 \mathrm{mmol})$, $\mathrm{Na}_{2} \mathrm{CO}_{3}(0.49 \mathrm{~g}, 4.6 \mathrm{mmol}), \mathrm{Pd}(\mathrm{dba})_{2}$ (3, 1, 0.1, or 0.01 mol\% with respect to the aryl bromide) and phosphine ligand 1, 2 or $\mathrm{PPh}_{3}[4,2$ or 1 equivalents with respect to the $\left.\mathrm{Pd}(\mathrm{dba})_{2}\right]$, were placed in a vial under nitrogen. $\mathrm{H}_{2} \mathrm{O}$ $(1.0 \mathrm{~mL})$ and $\mathrm{MeOH}(9.0 \mathrm{~mL})$ were added and the vials were placed in a pre-heated oil bath. At appropriate intervals, samples $(0.1 \mathrm{~mL})$ were taken and worked-up by adding $1 \mathrm{M} \mathrm{NaOH}(1.0 \mathrm{~mL})$ and $\mathrm{CH}_{2} \mathrm{Cl}_{2}(1.5 \mathrm{~mL})$ with thorough mixing. The organic layer was used for GC-analysis, using pentadecane as an internal standard. The aryl bromide, the cross-coupled product and the internal standard were detected by GC. No other (side) products were observed.

\section{References}

[1] R. Kreiter, R. J. M. Klein Gebbink, G. van Koten, Tetrahedron 2003, 59, 3989-3997.

[2] For reviews see: a) J. Hassan, M. Sévignon, C. Gozzi, E. Schulz, M. Lemaire, Chem. Rev. 2002, 102, 13591469; b) S. Kotha, K. Lahiri, D. Kashinath, Tetrahedron 2002, 58, 9633-9695; c) A. Suzuki, J. Organomet. Chem. 1999, 576, 147-168; d) N. Miyaura, A. Suzuki, Chem. Rev. 1995, 95, 2457-2483; e) V. Farina, $A d v$. Synth. Catal. 2004, 346, 1553-1582; f) N. T. S. Phan, M. Van Der Sluys, C. W. Jones, Adv. Synth. Catal. 2006, 348, 609-679.

[3] A. M. Rouhi, Chem. Eng. News 2004, 82, 49-58.

[4] N. Miyaura, Top. Curr. Chem. 2002, 219, 11-59.

[5] a) N. A. Bumagin, V. V. Bykov, Tetrahedron 1997, 53, 14437-14450; b) D. N. Korolev, N. A. Bumagin, Tetrahedron Lett. 2006, 47, 4225-4229; c) J. G. de Vries, A. H. M. de Vries, Eur. J. Org. Chem. 2003, 799-811; d) A. Alimardanov, L. Schmieder-van de Vondervoort, A. H. M. de Vries, J. G. de Vries, Adv. Synth. Catal. 2004, 346, 1812-1817.

[6] a) C. J. O'Brien, E. A. B. Kantchev, C. Valente, N. Hadei, G. A. Chass, A. Lough, A. C. Hopkinson, M. G. Organ, Chem. Eur. J. 2006, 12, 4743-4748; b) N. Marion, O. Navarro, J. Mei, E. D. Stevens, N. M. Scott, S. P. Nolan, J. Am. Chem. Soc. 2006, 128, 4101-4111.

[7] a) A. F. Littke, C. Dai, G. C. Fu, Angew. Chem. Int. Ed. 1998, 37, 3387-3388; b) A. F. Littke, C. Dai, G. C. Fu, J. Am. Chem. Soc. 2000, 122, 4020-4028; c) N. Kudo, M. Perseghini, G. C. Fu, Angew. Chem. Int. Ed. 2006, $45,1282-1284$.

[8] a) E. R. Strieter, D. G. Blackmond, S. L. Buchwald, J. Am. Chem. Soc. 2003, 125, 13978-13980; b) S. D. Walker, T. E. Barder, J. R. Martinelli, S. L. Buchwald, Angew. Chem. Int. Ed. 2004, 43, 1871-1876; c) J. P. Wolfe, R. A. Singer, B. H. Yang, S. L. Buchwald, J. Am. Chem. Soc. 1999, 121, 9550-9561; d) T. E. Barder, S. D. Walker, J. R. Martinelli, S. L. Buchwald, J. Am. Chem. Soc. 2005, 127, 4685-4696; e) K. L. Billingsley, K. W. Anderson, S. L. Buchwald, Angew. Chem. Int. Ed. 2006, 45, 3484-3488. 
[9] a) T. E. Picket, F. X. Roca, C. J. Richards J. Org. Chem. 2003, 68, 2592-2599; b) N. Kataoka, Q. Shelby, J. P. Stambuli, J. F. Hartwig, J. Org. Chem. 2002, 67, 55535566; c) J. F. Jensen, M. Johannsen, Org. Lett. 2003, 5, 3025-3328; d) S.-Y. Lin, M. J. Choi, G. C. Fu, Chem. Commun. 2001, 2408-2409; e) C. Baillie, L. Zang, J. Xiao, J. Org. Chem. 2004, 69, 7779-7782.

[10] Because of the presence of six benzyl amines in $\mathbf{1}$, we also tested this ligand without additional base. In this case some conversion is observed, but at a much lower rate than in the presence of additional base. When 2 was tested under base-free conditions, no conversion was observed at all.

[11] a) N. E. Leadbeater, M. Marco, Angew. Chem. Int. Ed. 2003, 42, 1407-1409; b) N. E. Leadbeater, M. Marco, $J$. Org. Chem. 2003, 68, 888-892; c) R. K. Arvela, N. E.
Leadbeater, M. S. Sangi, V. A. Williams, P. Granados, R. D. Singer, J. Org. Chem. 2005, 70, 161-168.

[12] A. Zask, P. Helquist, J. Org. Chem. 1978, 43, 16191620.

[13] Previously, the inhibitory effect of excess ligand on the coupling rate in the closely related Stille reaction has been termed the 'inhibition factor': V. Farina, B. Krishnan, J. Am. Chem. Soc. 1991, 113, 9585-9595.

[14] O. Niyomura, T. Iwasawa, N. Sawada, M. Tokunaga, Y. Obora, Y. Tsuji, Organometallics 2005, 24, 3468-3475.

[15] E. Genin, R. Amengual, V. Michelet, M. Savignac, A. Jutand, L. Neuville, J.-P. Genêt, Adv. Synth. Catal. 2004, 346, 1733-1741.

[16] R. Kreiter, J. J. Firet, M. J. J. Ruts, M. Lutz, A. L. Spek, R. J. M. Klein Gebbink, G. van Koten, J. Organomet. Chem. 2006, 691, 422-432.

[17] R. J. Angelici, (Ed. ), Inorg. Synth. 1990, 28, 110. 